\title{
The Effect of Employment and Working Place on Mood States of Employees
}

\author{
Dr. Bharat H. Mimrot*
}

\section{ABSTRACT:}

Now a day's police and civil Employees are working in under the stress. Employees are facing psychological problems and emotional stability and problem are increasing day by day. Low salary and job insecurity is becoming a serious problem and job attitude of Employees is changing and less satisfaction has been seen. In present study researcher has comprises the mood states to nature of employment and area of working place of police and civil employees in Aurangabad district. Main objectives of the present research are to study the mood states of employees serving in police and civil departments and study the mood states of urban and rural employees serving in police and civil departments. It was two hypotheses formulated that, there will be significant differences in mood states of police and civil employees and there would be significant differences in mood states of urban and rural employees serving in police and civil depts. The 400 police and civil employees were chosen by successive purposive sampling method from urban and rural area of Aurangabad district. Mood states questionnaire used (Dr. Mahesh Bhargva and Dr. S.D. Kapoor) for data collection. Two way ANOVA used for data analysis and results found that the significantly differences $(\mathrm{df}=1,396, \mathrm{P}<0.01)$ on mood states of employees. Hence concluded that area of working and nature of employment significantly impact on mood states of employees.

Keywords: Mood States, Nature of employment, area of working.

\section{INTRODUCTION}

There are number of Psychological researches related to behavioral aspects of human being of organizational field. Presents research is about police and local body Administration of organizational field. Now a day's police and civil Employees are working in under the stress. Employees are facing psychological problems and emotional stability and problem are increasing day by day. Low salary and job insecurity is becoming a serious problem and job attitude of Employees is changing and less satisfaction has been seen.

Head, U.G \& P.G Dept. of Psychology, NKSPT's Arts Sci and Com college, Badnapur, Dist. Jalna.

(C) 2014 B Himrot; licensee IJIP. This is an Open Access Research distributed under the terms of the Creative Commons Attribution License (http://creativecommons.org/licenses/by/2.0), which permits unrestricted use, distribution, and reproduction in any Medium, provided the original work is properly cited. 
To study police Employees Psychologically become necessary because of suicide case on Duty, Demolishing, antisocial activities, aggressiveness of seniors and this results in indicate imbalance of low order. In beside, Exploitation of citizens treating inferiorly, job in satisfaction, Corruption, various scandals, sexual Harassment by some civil employees of local body administration, force to study Psychologically Above said is to focus on mood states. It is necessary to study their state of mind psychologically.

\section{Mood states:}

The word "mood" has a wide range of usages and meaning. One might use the term to describe a phenomenological property of an individual's subjectively perceived affective state; e.g., someone may be in a cheerful mood or a hostile mood. One might also use mood to describe a property of an inanimate object; - e.g., a point-of-purchase display may have a "sophisticated mood" or a "fun mood.", we will adopt the former, phenomenological, approach and view moods as feeling states that are subjectively perceived by individuals. As such, moods are a subcategory of feeling states. The phrase "feeling state' will be used to, refer to an affective state that is general and pervasive. Such states "'suffuse all one's experiences, even though directed at none in particular" (Fiske 1981, p 231). These states can be contrasted with feelings directed toward specific objects, e.g., the affective component of brand attitude., Mood will refer to feeling states that are transient; such states are particularized to specific times and situations (Peterson and Sauber 1983) and may be contrasted with those that are relatively stable and permanent (Westbrook 1980)). Examples of invariant feeling states include personality dispositions such as optimist/pessimism (Gold man-Eisler 1960; Tiger 1979) and enduring global attitude structures such as satisfaction (Andrews and Withy 1976), moods may be distinguished from emotions, which, in contrast are usually more intense altention-getting and tired to a specifiable behavior (Clark and Isen 1982). One is almost always aware of one's emotions and their effects, which may redirect attention to the source of the emotion and interrupt ongoing behavior (Simon 1967). Different types of positive moods (e.g., cheeriness, peacefulness, and sexual warmth) and negative moods (e.g., anxiety, guilt, and depression) can be readily identified. Although categorizing moods as positive or negative may be an oversimplification (Belk 1984), existing research does not provide much insight into the effects of specific moods. In fact, most studies have involved broad manipulations designed to induce positive and/or negative moods and have not attempted to affect or assess specific moods. It is often difficult to infer the induced mood or its strength; e.g., subjects told that they have failed a test of perceptual motor skills may not respond emotionally or they may feel depressed, frustrated, or anxious. In addition, many common manipulations may fail to induce discrete moods, and naturally occurring feeling states may appear in clusters (Polivy 1981).

The most recent development in scientific psychology has been concerned with the psychology of emotions. The emotional life was considered better than the rational life because it was directly connected with the body. Those theorists of antiquity and feeling at all as psychological problems attributed them to a lower type of soul. The whole direction of our schooling in ethical 
problems and problems of correct behavior has been, until very recently, schooling in emotional inhabitation. The child must learn to control his loves and his hates, his fears and rages, his moods of excitement and depression despite the fact that civilization requires emotional control and emotional inhabitation most of us who are honest with ourselves realize that, were it not for the promise of certain emotional satisfaction. Life would be scarcely worth living at all.

No doubt many points in the older views regarding emotions were basically sound. It is quite obvious to everyone that must be curbed at sometimes and redirected at others. The modern view breaks with the order pre scientific view not at all another question of ethics but rather and questions as to the nature of the emotions. Emotions are today considered as natural phenomenon exactly as worthy of psychological study as any other form of behavior.

As the age grow young and old both may regress to infancy, to escape reality, becoming depended on others for care. Thus the emotional disturbances such as anxiety, depression, aggression, conflict, fatigue at quilt feeling, among peoples may be seen commonly in several cases.

\section{Previous Studies:}

Hart, Perter M (1999) examined a theoretical model that linked neuroticism, extroversion, daily hassles and uplifts in work and non work domains, job satisfaction and non work satisfaction to overall life satisfaction. Structural equation analysis was conducted on 3 waves of data obtained from 479 police officers. It was found that job satisfaction made independent contributions or overall life satisfaction but there was no significant relationship between work experiences and non - work satisfaction, non work satisfaction. These finding support a segregation model rather than a spillover model of the links between the work and non work domains of employees lives. More over the total effects showed that life satisfaction was determined, in order of importance, by non work satisfaction, job satisfaction, neuroticism, non work, hassles, job satisfaction, non work uplifts, extroversion work hassles and work uplifts. Kohan Andrea, Oconnor, Brian P (2002) examined job satisfaction, job stress and thoughts of quitting in relation to positive and negative effect, life satisfaction, self esteem and alcohol consumption among 122 police officers. Exploratory and confirmatory factor analyses revealed that 2 dimension's positive and negative effect provided a clear family tree organizational framework was primary associated with positive effect. Life satisfaction and self esteem; Job stress was primarily associated with negative effect and alcohol consumption thoughts of quitting and moderate loading on both factors. Kirmeyer, Sandra L (1988) investigated buffering role of social support in relationship of work load to tension anxiety and coping for police radio dispatchers. Found under high perceived load dispatchers with high social support engaged in more coping actions and felt less tension anxiety than did low - support dispatches. Evans, Barry - J, coman, - Gerg - J (1992) Examined stressors reported by police officers and correlated them with perceptions of their working environment and measurers of anxiety, Locus of control and mood states. 371 Australian police officers were administrated test that included a critical life events scale, the profile of mood states and the state - Trait Anxiety inventory stress was considered in terms of 
job content and job context. SS were stressed primarily by organizational variables common to occupational groups, such as rules, regulations and social ethos. Officers perception regarding the poor quality of supervision and he limited context to which they can to rely on supervisors constituted important organizational stressors. Trait anxiety was found to be an important variable in the job stress appraisal process. Data highlight the important of dimension between job contents and job context stress.

Main purpose of present study, researcher has comprises the mood states to nature of employment and area of working place of police and civil employees in Aurangabad district (M.S, India).

\section{PROBLEM}

"To comparative study of mood states of employees serving in police and civil department in Aurangabad district"

\section{OBJECTIVES}

Following are the main objectives of the present research:-

1. To study the mood states of employees serving in police and civil departments.

2. To study the mood states of urban and rural employees serving in police and civil departments.

\section{HYPOTHESES}

Following hypotheses are framed for the present study:-

1. There will be significant differences in mood states of police and civil employees.

2. There would be significant differences in mood states of urban and rural employees serving in police and civil depts.

\section{METHOD}

\section{A) Sample}

The sample was drawn from the population of employees working from Aurangabad district. The present study consists 400 respondents (200 policemen and 200 civil employees). Respondents were selected from Aurangabad district by Randomized method. All these respondents were matched for pay scale (a basic 4200 to 5700 ) educational qualification (12th to undergraduate), experience (10 to 15 year between) and age group (30 to 45 years). Sample consists of Police Head Constable (police employee) and Senior Clerks (civil employees).

Out of 400 respondents, 200 employees are serving in rural area of Aurangabad district since last five year and 200 urban employees serving area of Aurangabad city since at last five year. Sample of senior clerks were taken from collector office, Zillha Parishad office, Tahsil office and 
Panchayat samitee and policemen taken from various police station in Aurangabad district. Following table gives an idea of the sample.

\begin{tabular}{|l|l|l|l|}
\hline $\begin{array}{l}\text { Area of working } \\
\text { place }\end{array}$ & $\begin{array}{l}\text { Police employees } \\
\text { (Head constable })\end{array}$ & $\begin{array}{l}\text { Civil employees } \\
\text { (Senior clerk })\end{array}$ & Total \\
\hline Urban employees & 100 & 100 & 200 \\
\hline Rural employees & 100 & 100 & 200 \\
\hline Total & 200 & 200 & 400 \\
\hline
\end{tabular}

*Operational definitions of the terms used in the sample*.

\section{Civil employees}

Persons serving as senior clerk in Zillha Parishad, Panchayat Samitee, Tahsil office, and collector office are considered as civil employees.

\section{Police Employees}

Persons serving as head constables in police department of Aurangabad district are considered as police employees.

\section{Urban employees}

Employees serving in Aurangabad city are considered urban employees.

\section{Rural employees}

Employees serving at Taluka place in Aurangabad city are considered urban employees.

\section{B) Tools used for data collection:}

Mood States Questionnaire by Dr. M. Bhargva and Dr. Kapoor:- Researcher has used eight state questionnaire designed and prepared by Cattell and Curran (designed 1973 Curran in press) published by National Psychological Corporation at Agra. The eight state questionnaire (8 SQ) was specify for measuring eight important emotional states and moods i.e Anxiety, Stress, Depression, Guilt, Regression, Fatigue, Extraversion and Arousal. Reliability and Validity is very high and satisfactory of this questionnaire.

\section{C) Variables the under study:}

The present study was designed to find out the effect of independent variable and dependant variables. Following variables were studying:- 
Independent variable (Ivs):-

1. Nature of Employment (A):- A1 Police Employees

\section{A2 Civil Employees}

2. Area of working place(B):- B1 Urban Employees

\section{B2 Rural Employee}

Dependent variable (Dvs):- Mood States

\section{D) Research design}

In the present study researcher designed to study the Police employees and civil employees. This was belonging from Urban and rural areas. Therefore researchers framing the following type of $2 \times 2$ factorial design.

\begin{tabular}{|l|l|l|}
\hline \multirow{2}{*}{ Nature of Employment (A) } & \multicolumn{2}{|l|}{ Area of working place(B) } \\
\cline { 2 - 3 } & Urban (B1) & Rural (B2) \\
\hline Police employees(A1) & A1B1 & A1B1 \\
\hline Civil employees (A2) & A2B1 & A2B2 \\
\hline
\end{tabular}

\section{E) Procedure}

After establishing proper rapport with the subject, the Life satisfaction Scale and Eight State Questionnaire was administered on the sample in small groups of 20-25 employees in Aurangabad district. 


\section{STATISTICAL ANALYSIS AND RESULTS}

Researcher apply following properties for statistical treatment, descriptive statistics, twoway ANOVA and ' $t$ ' techniques will be used for data analysis to understand the mean difference between both groups of employees.

Table no: 1 shows the research design with sample size.

\begin{tabular}{|l|l|l|}
\hline Variables(Ivs) & Value Label & N \\
\hline Area of working & Urban employees & 200 \\
\cline { 2 - 3 } & Rural employees & 200 \\
\hline Nature of Employment & Police employees & 200 \\
\cline { 2 - 3 } & Civil Employees & 200 \\
\hline
\end{tabular}

Table No.02: shows two-way unvaried analysis of variance for dependent variable Mood states.

\begin{tabular}{|c|c|c|c|c|c|c|}
\hline Source & $\begin{array}{l}\text { Type III Sum } \\
\text { of Squares }\end{array}$ & Df & $\begin{array}{l}\text { Mean } \\
\text { Square }\end{array}$ & $\mathrm{F}$ & Sig. & $\begin{array}{l}\text { Partial Eta } \\
\text { Squared }\end{array}$ \\
\hline $\begin{array}{l}\text { Area of } \\
\text { working }\end{array}$ & 10475.523 & 1 & 10475.523 & 52.621 & 0.01 & 0.117 \\
\hline $\begin{array}{l}\text { Nature of } \\
\text { Employment }\end{array}$ & 1975.802 & 1 & 1975.802 & 9.925 & 0.01 & 0.024 \\
\hline $\begin{array}{l}\text { Area of } \\
\text { working X } \\
\text { Nature of } \\
\text { Employment }\end{array}$ & 1517.103 & 1 & 1517.103 & 7.621 & 0.01 & 0.019 \\
\hline \multirow[t]{2}{*}{ Error } & 78833.970 & 396 & 199.076 & & & \\
\hline & 92802.4 & 396 & & & & \\
\hline Total & 3392293.000 & 400 & & & & \\
\hline
\end{tabular}

p- $0.05=3.86 \quad 0.01=6.70$

Eta squared $=0.01=$ small effect; $0.06=$ moderate effect $0.14=$ large effect

In the above table two-way unvaried analysis of variance it is shown that the first main effect of area of working i.e urban and rural .The value $F(1,396)=52.621$. which is significant on 0.01 level Hence it indicate that urban and rural employees showing significant difference about mood states and Eta squared value is 0.117 , showing moderate effect and variance is '1.1'. 
Second main effect is nature of employment i.e police and civil employees the value $\mathrm{F}(1,396)=$ is $9.925(\mathrm{df}=1,396)$. Which is significant on 0.01 level. Hence showing significant difference about mood states and Eta squared value is 0.024, Showing small effect and variance is'0.2. The interaction effect showing significant difference about mood states "F" value is 7.621 its significant on 0.01 level and eta squared value is 0.019 showing small effect and its variance is 0.1 .

For the critical analysis, researcher analyzed Post-Hoc test as " $t$ " test.

Table No.3: shows difference between civil and police employees for dependent variable mood states.

\begin{tabular}{|c|c|c|c|c|c|}
\hline Group & $\mathrm{N}$ & Mean & SD & $\mathrm{T}$ & $\begin{array}{l}\text { Significance } \\
\text { Level }\end{array}$ \\
\hline Civil & 200 & 93.04 & 15.623 & \multirow[b]{2}{*}{2.9403} & \multirow[b]{2}{*}{0.01} \\
\hline Police & 200 & 88.60 & 14.572 & & \\
\hline Urban & 200 & 95.94 & 12.294 & \multirow{2}{*}{7.1130} & \multirow{2}{*}{0.01} \\
\hline Rural & 200 & 85.71 & 16.204 & & \\
\hline
\end{tabular}

In the above table the mean value of civil employee is 88.60 and $\mathrm{SD}$ is 14.572 as well as the mean value of police employee is 93.04 and SD is 15.623. Obtained ' $t$ ' value is 2.9403 . Which is significant on 0.01 level. On the basis of mean it is concluded that the level mood states high in police employees than civil employees. And accept third hypothesis "There will be significant differences in mood states of police and civil employees". The mean value of urban employee is 95.94 and SD is 12.294 as well as the mean value of rural employee is 85.71 and SD is 16.204. Obtained' value is 7.11. Which is significant on 0.01 level. Hence, it is concluded that the mood states level high in rural employees and urban employees. And accepts hypothesis fourth, there would be significant differences in mood states of urban and rural employees serving in police and civil depts.

\section{DISCUSSION:}

Hypothesis No. 01: "There will be significant differences in mood states of police and civil employees."

As per table No 2 and 3, the means of mood states score are 93.04 and 88.60 respectively for the police and civil employees, the main effect of employment is significant for mood states $(\mathrm{F}=9.925$, df-1,396, $\mathrm{P}<0.01)$. The policemen scored higher on mood states than civil 
employees, the results supported hypothesis. The effect size (partial eta square) for the main effect of nature of employment on mood states is small (0.024) meaning that nature of employment explains $0.2 \%$ variance for mood states. The results of indicate that the mood states levels is higher in policemen than civil employees.

Police employees have high mood state level than civil employees. In present research the mixed results are found in the term of stress, Anxiety, arousal and fatigue. In short there is interrelationship between work/job factors psycho-social factors end may be because of these above results are founds.

Hypothesis No. 2: "There would be significant differences in mood states of urban and rural employees".

As per table 2 and 3, the mean of mood states scores are 95.94 and 85.71 respectively for the rural and urban employees. The main effect of area of working is significant $(\mathrm{F}=52.621$, $\mathrm{df}=1,396, \mathrm{P}<0.01$ ) for mood states. The rural employees mean scored higher on mood states level than urban employees. The results support hypothesis 20. The effect size (partial eta square) for the main effect of area of working on mood states is large (0.11), meaning that area of working explains $1.1 \%$ variance for mood states. The results indicate that the mood states levels is higher in rural employee than urban employees. The mood states level is found to be more in rural employees than urban employees. From the different view of thinking mental stress is emerged. If the working place is far way from head office then the orders and information of senior officers are not cleared. The orders and information of senior officer are unclear because of for distance between working place and head office. Hence employees get pressured shed work. The job distribution is beyond capacity of the employees due to which pressure of job is increased. Having the lack of facilities, job status is getting decreased. The fulfill needs of family; salary is not

sufficient as compare to job. Always not only due to economical problem but also work responsibility, the employees are getting seek or hectic.

\section{CONCLUSIONS:}

1. The mood states level is higher in policemen than civil employees.

2. The mood states level is more in rural employees than urban employees. 


\section{SUGGESTION:}

Following attempts are made to help employee's better manage the personality:-

1. To Design of programs and activities to increase officer participation in decision making and improve the quality of work life through enhanced communication.

2. Establishment of specific police stress programs such as psychological services health/ nutrition programs and exercise programs.

3. Development of peer-counseling programs.

4. Development of operational policies that are directed at reducing stress (scheduling, work hours, workload etc)

5. Development of managerial skills that are people oriented.

6. Use of relaxation and other stress reducing techniques.

7. Use of spouse/family/involvement programs.

8. Communicate policies effectively to publics and officers.

9. Treat all citizens with respect and preserve human dignity.

10. Values are designed as beliefs and principles by which the people department fulfills responsibilities.

11. Decreasing working hours, workload and Govt. give to optimum values of work.

\section{LIMITATIONS:}

1. The present study is limited to mainly police employees, who are serving in as of head constable and civil employees, who are serving in as senior clerks from the local administration sector.

2. The study has been delimited with respect to sample. The size of the sample is drawn from the various Police-stations in the Aurangabad city and taluka place.

3. The age group of the sample is in between 25 to 45 years $\&$ all over ss is married.

4. There are no considerations for sex difference in the present research.

5. Present study is only limited on Aurangabad District. 


\section{REFERENCES:}

1. Andrew\& Frank and Slephen Withey( 1976): Social Indicators of well-being. New York: Plenum Press.

2. Barry J. Evans, Greg J. Colman (1992) : The Police Personality Type A behavior and trait anxiety. Journal of Criminal Justice vol-20, Iss-5, Page 429-441.

3. Belk(1984): Applications of Mood Inducement in Buyer Behavior. Advances in consumer Research. Vol. 1 I ed Thomas kinnear, Provo. UT: Association for Consumer Research, 544-547.

4. Fiske, Susan ( 1981 ): Social Cognition and Affect. Cognition, Social Behavior and the Environment, ed. John Harvey, Hilisdale, NJ: Lawrence Erlbaum, 227264.

5. Goldman-Eisler, Frieda ( 1960): Breastfeeding and Character Formation. Personality in culture, Society, and Culture, eds. C. Kluckholn and H. Murray, New York: Alfred A. Knopf.

6. Hart P.M. (1999): Predicting employee Life satisfaction. Journal of applied Psychology, Vol-84 n (4).

7. Kirmeyer, Sandra L. (1988) : Work load, Tension and Coping. Personnel Psychology, Vol-41, No-1 Page 125-139.

8. Kohan Andrea; O. Connor - Brian P (2002) : Police Officer Job Satisfaction in relation to mood, well-being. Journal of Psychology Interdisciplinary and applied, Vol-136(3), pp. 307-318.

9. Peterson, Robert and Matthew Sauber ( 1983): A Mood Scale for Survey Research,. In 1983 A M.A Educators Proceedings, eds. Patrick Murphy etal. Chicago, IL American Marketing Association, 409-414.

10. Polivy ( 1981 ): On the Induction of Emotion in the laboratory: Discrete Moods or Multiple affective States?. Journal of Personality and Social psychology 41 (October), 803-817.

11. Simon ( 1967):Motivational and Emotional Controls of Cognition. Psychological Reviews, 74 (I), 29-39.

12. Tiger ( 1979): Optimism: The Biology @ Hope, New Yark: Simon and Schuster. 